who regarded social ethics as the livest of topics. The Faculty has become the recognized consultant and training ground on all matters, local and national, of industrial administration.

Another organisation also recently outgrowing its ancestry is the Institute of Education under Prof. M. V. C. Jeffreys, the research centre to which look the training colleges and education authorities of the Midland counties. The most widespread of these extensions of University influence outside its walls is the Extra-Mural Department, under D. R. Dudley, who controls many part-time and full-time tutors of hundreds of classes throughout the Midland counties : a feature distinguishing this from the earlier Workers' Educational Association and 'university extension classes' is the inclusion at a high level of specialist postgraduate courses and residential week-ends serving as refresher courses to professional men and women who feel in danger of losing touch with the rapid growth of their subjects since student days.

The welding of all these enterprises, many completely new in this generation, into a loyal and friendly community is due to the personality of the present vice-chancellor, Sir Raymond Priestley. Besides the more usually recognized academic duties, he has made a unique place in modern university administration by his constant and shrewd understanding of undergraduate life and feeling; although maintaining closer touch with students than most academic heads, he has insisted on student autonomy in the managing of their own buildings and laws and finances, to an extent not known elsewhere. He has also created the Department of Physical Education. Under its head, A. D. Munrow, the staff of this includes men and women of international fame as athletes who are moreover distinguished for their wisdom and insight into student needs. There are two full-time medical officers, available to the whole University, and there is a highly organised office of the Lodgings Warden; it is no longer possible to reproach the provincial university, so far as Birmingham is concerned, with caring little what happens to the student outside of class and exam. ination.

The barrier now obstructing Birmingham's full utilization of these expanding schemes is lack of buildings : it has residential halls for not more than three hundred of its 3,500 students, and even the teaching in arts and law remains in the outworn building which was Mason College in the city centre. Before the War the rehousing of these faculties alongside the great scientific and medical buildings at Edgbaston, three miles out, was about to begin, and there is land in plenty on the site; but in a city where 100,000 buildings were bomb-damaged and where 40,000 families await domestic rehousing, it is obvious that licences and materials for such largescale academic construction are bound to be drastically in arrear. In fact, small additions to the buildings for medicine and physics, and the rebuilding of those for mechanical and electrical engineering and industrial metallurgy, are the only walls now new. But the problem is not only "How can a government assign priorities ahead of housing ?", and the Midlands are also beginning to ask, "Can the community afford to delay longer the unifying of a great academic centre on a single site, the fusing of all faculties into that common mind of scholarship without which the University's service to the public is crippled ?"

\section{THE SCINTILLATION OF STARS}

TN two recent communications ${ }^{1}$, Prof. H. Hartridge 1 expresses doubt about the physical explanation of the scintillation of stars. Now these phenomena have been extensively studied in a series of classical papers which are reviewed and summarized in $\mathbf{6 3}$ pages of Pernter-Exner's "Meteorologische Optik" (Wien, 1922), or in Danjon's "Lunettes et Télescopes" (Paris, 1935), and there would be little point in repeating explanations so well established. The observations which Prof. Hartridge requires as a test have already been made and fully confirm the physical theory.

(1) Movements of the star images at right-angles to the line of sight are not visible to the naked eye because they are too small, but they are known to every astronomer. They have been recorded as a function of time by Schlesinger ${ }^{2}$ and by other authors, and are found to be of the order of a few seconds of arc.

(2) Prof. Hartridge expects that these star movements should take place preferentially in the direction of the wind. This is a misapprehension; the striæ follow the wind, but the refraction is at random. This motion of the stria is evidenced by the undulations at the limb of the sun and by photographic records ${ }^{3}$.

(3) Prof. Hartridge expects that owing to sointillation the star images would be drawn out into spectra. This is a widespread misconception. The displacement of the star being so small, an additional dispersion effect would be wholly unobservable. The origin of the coloured scintillation is the regular atmospheric refraction, due to which a green ray and a red ray of the star travel at an increasing distance from each other, and so pass through different striæ and scintillate independently. Very interesting spectral phenomena of the scintillation, noted by Respighi, are slightly more complicated but can be satisfactorily explained.

(4) A comparison between the scintillation as observed by the right and by the left eye is very difficult, and requires a great deal of practice. R. W. Wood was able to observe the difference between the scintillation for the left and for the right eye, which proves that most striæ are smaller than $7 \mathrm{~cm}$.

(5) A stereoscopio effect cannot be expected (a) because the lateral displacements are unobservable with the naked eye anyway; (b) because the phenomenon is much too rapid to permit of binocular adjustment.

(6) Prof. Hartridge does not see how the physical theory could explain the observed variations in brightness. These variations in brightness are due to variations in the convergency or divergency of the rays; it can be shown quantitatively that the small changes in direction may cause considerable variations in brightness. These variations have been recorded on a photographic plate ${ }^{3}$ and may be demonstrated with a photocell and a cathode ray oscillograph. I wonder how physiology would explain the striking difference in scintillation between stars at high and at low altitude above the horizon.

As to physiological phenomena, I would not like to reject them altogether. It is said that stars are seen to scintillate somewhat more in the twilight; also, that reddish stars seem to scintillate more than 
white ones. Such details may perhaps be accounted for by physiology.

Sterrewacht "Sonnenborgh",

\section{Minnaert}

Utrecht.

${ }^{1}$ Nature, 164, 999 (1949) and 165, 146 (1950).

${ }^{2}$ Mon. Not. Roy. Astro. Soc., 87, 506 (1927). Strömgren, B., Festskr. Norlund, 1945; etc.

s. Minnaert and Houtgast, Z. Astrophys., 10, 86 (1935).

NONE of the correspondents writing on this subject appears to have taken into account the fact that, as viewed by most people, most of the stars do not scintillate when observed with the naked eye from a point within the tropics. This at any rate is my clear recollection after spending more than three years in the tropical zone.

Daneway, Rothley Plain, H. F. H. JONES Leics.

Prof. Hartridge ${ }^{1}$ may well inquire whether a subjective element contributes to the scintillation of stars, for there is more in twinkling than meets the eye. But tremulous images are not entirely due to the observer; they can be detected by the photographic plate. Schlesinger ${ }^{2}$ discovered changes in atmospheric refraction which give rise to small oscillations of the telescopic image, with an amplitude of about $l^{\prime \prime}$ and a period of about 1 min. Even zenith stars are affected ${ }^{3}$, though to a less extent and with a shorter period. The effect on twinkling caused by these irregularities of refraction could perhaps be determined by visual and photographic measures made simultaneously.

On the other hand, Prof. Hartridge will derive support for his ideas from the motion of 'jumping stars' (the so-called Sternschwanken), into which, in some cases at least, a subjective element would seem to enter, especially when the eye is tired. As regards dispersion, stars near the horizon sometimes appear to be drawn out into short spectra; at smaller zenith distances the dispersion would not be appreciable.

\section{King's Collegə,}

KENNETH HARRISON

Cambridge.

${ }^{1}$ Nature, 165, 146 (1950).

${ }^{2}$ Schlesinger, F., Mon. Not. Roy. Astro. Soc., 87, 506 (1927).

${ }^{8}$ Barocas, V., and Withers, R. M. J., Observatory, 68, 153 (1948).

4 Weyer, G. D. E., Astro. Nachricht., 119, No. 2841 (1888).

Tue observations of scintillation of stars reported by Gregory and by Morton ${ }^{1}$ can be extended and confirmed by simple experiments. Using either fieldglasses or a hand telescope, the image of a star such as Sirius ean be made to move rapidly in circles over the retina. By controlling the shaking of the hands, the period of the movement and the size of the circles can be varied at will. The image of a star then appears as a circle of light, and the scintillation is seen as variation in the brightness and the colour of different parts of the circle.

If stellar scintillation were largely a retinal phenomenon, as suggested by Hartridge and Weale ${ }^{2}$, the pattern on the circles would be expected to vary little with changes in the period of oscillation of the image, or the size of the circles traced out. If the effect is largely atmospheric, the rapidity of the brightness changes will not be affected by the movement, so that the appearance of the bright lines on the retina will change from lines of coloured dots to coloured streaks as the speed of movement of the image increases. This is found to be so. Scintillation is very obvious with bright stars like Sirius down to those in the Pleiades, even in a telescope giving a magnification of $\times 20$. Planets show scarcely any trace of this effect.

Morton's observation of Sirius through misted glass can readily be repeated by defocusing, and the defocused image can be moved as before. Scintillation is still visible, and is clearly almost synchronous over the whole disk of the image. Although the 'boiling' effect mentioned by Gregory shows as an occasional flash in the width of the ribbon of light, flashes must cover hundreds of times the retinal area covered by the image of the star when in focus.

It would be interesting to know what effects could be observed with Prof. Hartridge's apparatus if his small bright light were viewed in a slightly agitated mirror.

Jesus College, Oxford.

G. C. VARLEY

1 Nature, 165, 146 (1950).

Nature, 164, 999 (1949).

There are a few simple experiments, perhaps not widely known, which have a bearing upon the physical interpretation of this phenomenon.

We have at the Royal Observatory, Edinburgh, a 6-in. objective prism set up in combination with a 5-in. aperture $f 5$ camera lens. The spectrum of Sirius on a 'scintillation' night appears as a narrow line of rainbow colours about $\frac{3}{8}$ in. in length. Viewed through a low-power lens, the light in any part of the spectrum appears to show little fluctuation. If the viewing lens is now given a rapid vibration of small amplitude in the direction at right angles to the plane of dispersion, so that the spectrum is broadened and separated out into its time elements, a most surprising effect is seen. Each of these elementary spectra has one or more broad regions of colour missing : some exhibit only red and violet, others green or blue, and so on. Moreover, each of these patterns is seen to be changing along the length of the spectrum with great rapidity and in an apparently haphazard fashion. When the lens stops vibrating the time elements become superposed and the eye integrates, by the persistence of vision, all these instantaneous patterns, so that we obtain once more what is the normal state of affairs, a steady continuous spectrum. It seems that this phenomenon was first reported by Respighi in 1872 .

We must infer, therefore, that when we observe a scintillating star directly, either with the unaided eye or through a small telescope, the 'white' image which we see is, in fact, composed of a succession of colours changing at such a high frequency that the eye is unable to distinguish them separately. If this be correct, it follows that we should be able to observe these colour changes in the image of a star if only we could separate them out on a time base.

Now this can be done by very simple means. Take a pair of prismatic (or Galilean) binoculars, focus on Sirius, or any other lst mag. star at low altitude. Then give by hand to one end of the instrument a rapid rotary motion, so that the star image appears to be drawn out around the circumference of a small circle, oval, or figure-of-eight. The observed effect is one of extreme beauty: the line of light is seen to be divided up into a splendid array of sparkling colours. 